\title{
Effect of Green Tea in Decreasing Electromagnetic Waves Damages
}

\author{
Zahra Zahedifar $^{1, *}$; Javad Baharara ${ }^{2}$ \\ ${ }^{1}$ Department of Biology, Mashhad Branch, Islamic Azad University, Mashhad, IR Iran \\ ${ }^{2}$ Department of Biology, Mashhad Branch, Islamic Azad University, Mashhad, IR Iran \\ *Corresponding author: Zahra Zahedifar, E-mail: zahrazahedifar@yahoo.com
}

Received: November 13, 2013; Accepted: December 25, 2013

\begin{abstract}
Context: Possible effects of physical and chemical environmental pollutants in modern industrial life on human health concern about one of the largest problems for scientific organization and the government. About 60 newest published articles results have been studied in last decade (2002-2013) in this research about inhibitory effects of green tea on electromagnetic waves damages. Then we have been used about 40 of them in this review article.

Evidence Acquisition: For this aim, we searched some key words such as environmental damages, electromagnetic waves, antioxidant effects and anticancer effects of green tea in Science Direct, Springer and Elsevier.

Results: Nowadays, scientists' effort to use natural ingredient instead of drugs and chemicals to maintain human health more and prevention of diseases. Among such, consumption of green tea has the longest history in the world and now in over 160 countries around the world as the common beverage is consumed daily.

Conclusions: Recently, green tea due to its numerous benefits in health, in prevention and in treatment of diseases such as cancer has been considered in the public opinion and in the scientific community. Because of its application, in addition to traditional methods of brewing has prevalence as a natural ingredient in food or feed products and in the pharmaceutical and cosmetics industries.
\end{abstract}

Keywords:Electromagnetic Radiation; green tea extract polyphenone E; Health

\section{Context}

Electromagnetic radiation of low frequency and very low frequency have been increased in our environment due to the wide spread use of electrical devices (1). It seems that more radiation in our environment acts in the frequency range between $0 \mathrm{~Hz}$ to $300 \mathrm{kHz}$ (2). Cell phone technology acts according to electromagnetic radiation in the frequency range of microwave $(300 \mathrm{MHz}$ to $300 \mathrm{GHz}$ ) (3). The effects of different frequencies are investigated on biological systems at all levels of an organism until a biological molecule. Several conflicting reports are presented about effects of electromagnetic fields on genetic material and biological processes in living organisms. It seems that the energy of electromagnetic fields physically and directly is not able to break the single-strand or double strand of DNA on cells that were exposed to radiation (4). Many studies show that electromagnetic fields with the change in the function or stages of the cells induce a variety of responds in organisms (5). Excessive electromagnetic radiations have created many concerns about the harmful possible effects of electromagnetic fields on the health of living beings, particularly humans. So that, today it can be considered one of the largest concerns of health officials and researchers in different communities. For this reason, scientists are searching for natural alternatives instead of chemicals to maintain health, prevent and treat a variety of diseases.
Green tea (Camellia sinensis) is a perennial evergreen plant that is consumed as beverages, food or natural compounds in food, pharmaceutical and cosmetics industry that have become popular again (6).

\section{Evidence Acquisition}

Based on studies, the antioxidant and pro-oxidant properties of green tea may reduce the genotoxic effects of harmful electromagnetic radiation. We have discussed about some of these studies results.

New published results about inhibitory effects of green tea on damages that caused by electromagnetic waves are investigated in this paper. For this aim, about 60 newest published articles results in last decade have been studied. Then we have been used 40 of them in this article. Several key words such as tea, green tea, antioxidant effects, anti- cancer effects, anti-electromagnetic radiation effects, electromagnetic waves and its characteristics, the effects of genotoxic electromagnetic radiation and mechanisms of action have been used in this study.

\section{Results}

The chemical composition of green tea are different suitable with the weather, season, humidity, material culture, leaf position on the plant, species, age and its production

Copyright (c) 2015, Zahedan University of Medical Sciences. This is an open-access article distributed under the terms of the Creative Commons Attribution-NonCommercial 4.0 International License (http://creativecommons.org/licenses/by-nc/4.0/) which permits copy and redistribute the material just in noncommercial usages, provided the original work is properly cited. 


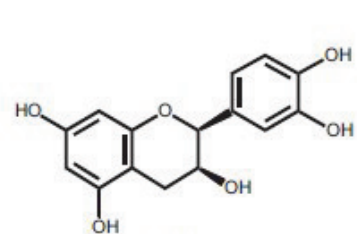

Epicatechin (EC)

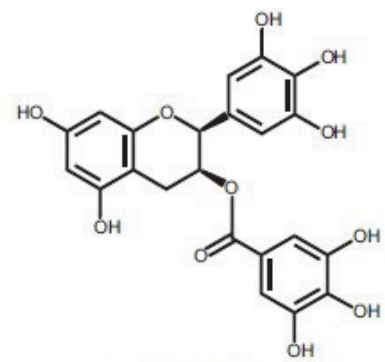

Epicatechin-3-gallate (ECG)

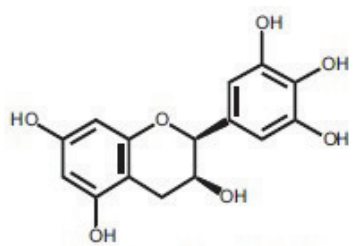

Epigallocatechin (EGC)

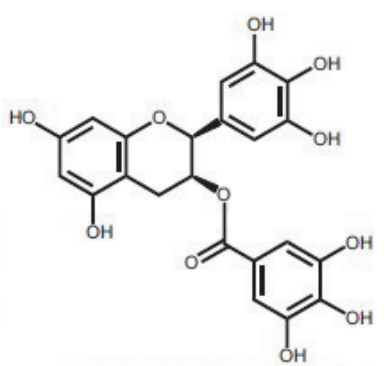

Epigallocatechin-gallate (EGCG)
Figure 1. Chemical Structures of Green Tea Polyphenols

processes (7). Green tea contains a wide variety of antioxidants, such as vitamin A, vitamin C, vitamin B, vitamin $\mathrm{E}$ and a variety of polyphenols (8) (Figure 1).

Green tea has 30\% polyphenols, such as flavonol, flavone Deol, flavonoid, phenolic acid, glycoside and catechin (9). Green tea extract contains high levels of natural antioxidants polyphenols specially catechin which is rapidly absorbed into the body and it has been demonstrated anti cancer, anti microbial, anti inflammation and anti radiation waves properties for it. There are four main groups of catechin in the leaves of green tea. Catechin polyphenols are such as epicatechin (EP), epigallo catechin (EGC), epicatechin gallate (ECG) and epigallocatechin gallate (EGCG). Antioxidant activities of catechins increase in this way EC $<$ EGC < ECG < EGCG (10). It seems that 30\% of the weight of green tea leave contains these polyphenols. Among this polyphenols, epigallocatechin gallate is the most important and it is the most active ingredient that includes $50 \%$ of the total catechin content. More antioxidant action in green tea is attributed to the EGCG and ECG, because these compounds have two polyphenols groups in their structures. It seems that there are a relationship between their structural properties and antioxidant abilities (10). Leaf bud and primary leaves have a lot of EGCG and its antioxidant properties is 25-100 times more than vitamins $\mathrm{C}$ and $\mathrm{E}(8)$.

To prepare a cup of green tea, allow $2 \mathrm{~g}$ of tea dried leaves with $200 \mathrm{~mL}$ of hot water $\left(70-80^{\circ} \mathrm{C}\right)$ for $5-7 \mathrm{~min}$. Catechin comprises approximately $30-40 \%$ of leaf tea in this method (11). Reports of Miyagishima et al. also show that green tea contains a large amount of ascorbic acid and vitamin $\mathrm{E}$, therefore it has the most strong antioxidant properties than these vitamins (12). Anti cancer, anti oxidative, anti inflammatory, anti carcinogenic, pro oxidant and antioxidant properties of green tea are notified in many different studies (13). Antioxidants by destroying free radicals protect body against their adverse effects and green tea is rich in natural catechin antioxidant with high potent to relieve free radicals (14). Green tea also has properties such as anti allergy, inhibition of plaque formation in the brain, inhibitory effect of waves, deduction of glucose and triglyceride, blood cholesterol, inhibition of the body fat accumulation, stimulating catabolism of fat in the liver and increase the use of the body energy (7, 15). Reduction of cardiovascular diseases, in body weight, in fuel, in excess fat and improvement in diseases such as diabetes, Alzheimer, Parkinson and various types of cancer, prevention of tooth decay, the gout, antimicrobial activity and lipid peroxidation are attributed to the biological activities of green tea polyphenols (16). But more emphasis has been discovered on the anticancer effects of green tea and its biochemical mechanism (17). The aim of this paper is to investigate the effects of green tea in reducing genetic damages that induced by environment electromagnetic radiation.

Inhibitory effects of green tea on physical pollutants: Local function of epigallocatechin gallate can inhibit induction effects of UV- on precancerous cells and it can destroy induction changes in these cells (16). Green tea prevents the inhibitory effects of UV radiation on DNA repair and stimulates killer $\mathrm{T}$ cells to prevent development of skin cancer that resulting from environmental pollutants (16). Kubota et al. with treatment fertilized eggs that exposed to UV- radiation with green tea, has described the mechanism of its inhibition. Catechin due to its hydrophilic property set on the external surface of the plasma membrane, whereas free radicals induced by radiation are hydroxyl type and is formed near the membrane surface. These free radicals enter in the cell membrane and induce lipid peroxidation. But tea catechin degrades the outer part of hydroxyl radicals and reduces its adverse effects in the cell (18). Green tea with induction of IL-2 (a kind of cytokine that regulates the immune system) and speed up repairing of DNA damage and inhibition of carcinogenesis onset of skin cancer also prevents non-melanoma that induced by -ultraviolet radiation (19). Liu and Yu have also proven that green tea inhibits neuronal damage induced by ultraviolet radiation in rat cortical neurons that induce ulcer (20). $\mathrm{Hu}$ et al. measurements the hemoglobin level, number of erythrocytes and leucocytes of mice before and after they exposed to gamma radiation for 21 days and he has reported severe reduction of these cells in comparison with the control group. However, treatment with doses of 50 and $100 \mathrm{mg}$ of green tea extract for 28 days after irradiation and remeasurement of hemoglobin, erythrocytes and leucocytes showed that green tea decreases intensity of demolition that induced by gamma radiation in hematopoietic system (21). A study has shown that a Guinea pigs exposed to $900 \mathrm{MHz}$ of cell phone radiation are scattered cardiac autonomic adjustments, but green tea has beneficial effects on endothelial function and re- 
duce the risk of cardiovascular (14). By using of green tea catechin can prevent microwave oxidative damages on cardiac tissue (13).

Studying about effect of green tea catechin on enzyme activity and gene expression in rats liver antioxidative system that were exposed microwave show that the mice were treated with catechin were such as controls and liver damage and its performance depend on the balance between catechin antioxidative systems. In this experiment, a group treated with catechin $25 \%$ and a group treated with catechin 50\%. Glutathione peroxidase activity in both groups had no significant differences with each other and with the control group after 16 days (15).

Studying about effect of green tea catechin on enzyme activities and genes expression of anti oxidative systems in rat liver that coincide with the consumption of green tea for $15 \mathrm{~min}$ during the 16 day exposure to 2.45 $\mathrm{GHz}$ microwave frequencies have been indicated that the degree of liver injury in this group had not significantly different with the control group (22). Studies about use of green tea on liver and testis cells of pigs that exposed to $900 \mathrm{MHz}$ cell phone electromagnetic waves have been shown that electromagnetic can change levels of minerals such as iron, manganese and zinc in tissues but green tea return them to normal level (23). Studying about protective effect of green tea polyphenols against induced lesions of electromagnetic radiation in cortical neurons of rats that were exposed to $1800 \mathrm{MHz}$ of cell phone for 24 $\mathrm{h}$ also indicate that microwave induce apoptosis marker in this neurons and green tea improves and repairs these wounds (24). Increase chromosomal damages on bone marrow polychromatic erythrocytes and lymphocytes, heart, liver, spleen and brain and increase the risk of cancer in laboratory animals that were exposed to cell phone radiation and extremely low frequency electromagnetic fields have also been reported in other studies (25-27).

Baharara et al. have reported an increased micronucleus frequency in peripheral blood erythrocytes of newborn Balb/c mice whose mothers were exposed to cell phone radiation $940 \mathrm{MHz}, 8 \mathrm{~h}$ daily during pregnancy (27). In another experiment he also placed the Balb/c pregnant mices from day 14 of gestation at cell phones $940 \mathrm{MHz}$ radiation for 4 days, $6 \mathrm{~h} /$ day and he has reported increased micronucleus frequency in peripheral blood erythrocytes of 2 day infants and their mothers but he has not been observed increased micronucleus frequency in 18.5 day embryos and their mothers (28). In other study, i.p. injection doses of 100 and $200 \mathrm{mg}$ of green tea extract for 5 days and exposure to cell phone radiation for 4 days, (3 hours/day) show that cell phone radiations could increase the number of micronucleus in polychromatic erythrocytes on mice bone marrow, but green tea had inhibitory effect and reduce the frequency of micronucleus (29). Comparison mice that treated with doses of 100 and $200 \mathrm{mg}$ of green tea extract for 5 consecutive days with sham exposed animals show that green tea destroys free radicals inhibits oxidative stress and prevents DNA dam- age, so it prevents formation of micronucleus on mice bone marrow polychromatic erythrocytes (29). Inhibitory effect of green tea extract has been studied in reduction of induced teratogenicity low frequency electromagnetic fields on bone marrow, spleen and liver of the mouse embryo (30). In fetal that exposed to low intensity electromagnetic field were seen an increase in weight, in length of crown-seat and the average number of megakaryocytes in the liver and spleen, while it is found to be lower increased in the treated group with green tea. The effect of green tea extract injected in spleen lymphocytes is observed too, because green tea extract reduced cell number caused by electromagnetic field and compensate return to normal level (30). Chan et al. compared superoxide dismutase and catalase enzyme activities in lung cells of mice that were exposed to cigarette smoke $(40 \mathrm{~mL} / \mathrm{min}$ ) for $1 \mathrm{~h}$ during 56 days and treatment with green tea $(5 \mathrm{~mL}$ dose twice daily before and after smoking) with control group in ordinary air and obtained similar results. This indicates health positive effects of green tea against physical and environmental pollutants (31). Green tea with inhibition of releasing induced free radicals by radiofrequency radiation cause oxidative stress in liver proteins. Male guinea pigs were exposed to cell phone radiation $1800 \mathrm{MHz}$ with $\mathrm{SAR}=0.81 \mathrm{~W} / \mathrm{kg}$ for 20 $\mathrm{min}$ in a day (20 min/day) during one week and increasing antioxidant enzyme activity and reducing free radicals were measured in an experiment (4). It seems that electromagnetic waves produce reactive oxygen species and decrease antioxidant enzyme activity in the cells and antioxidants such as melatonin, vitamin C, vitamin E and green tea prevent oxidative stress and cause apoptosis in damaged cell (4). Green tea also reportedly Zahedifar et al. has a very strong inhibitory effect on deletion mutations in mitochondrial DNA of human blood lymphocytes that were exposed to ultraviolet waves (29). Erba et al. also has referred in his experience to a decrease in DNA oxidative damage that induced in human lymphocytes (32).

Mechanisms: Many inhibitory mechanisms of green tea depend on antioxidant and pro oxidant properties of it. Green tea catechins are among the best chemical antioxidants that act through the destruction of free radicals and induce oxidative stress and pro oxidants are also responsible for apoptosis and induce typically intracellular antioxidant systems in cells that resistance against the destructive elements (7). Some researchers believe that catechin oxidation and severe inclination of it to proteins are responsible for protein carbonyl formation and the differences in these properties and chemical structures of catechins could create pro oxidant biological activities of it. In this study, the antioxidant activity of green tea is attributed to catechin action against the free radicals but in some another researches, inhibitory is dependent on pro oxidant performance of it and also depend on to green tea catechin interaction with target proteins (7). Most antioxidants have anti cancer function; they have the pro oxidant and pro apoptic activities at high doses. Thus, high doses 
of catechin trigger apoptosis in cancer cells and in lower concentrations do neuronal protection against a broad spectrum of toxic and nervous agents. In fact, this antioxidant activity alters cell signaling pathways and can effect on the ability of cell survival. Some believe that the antioxidant effects of polyphenols induce oxidative stress and pro oxidant effects are responsible to induced apoptosis and totally inhibit the cancer and chromosomal damages (10). Babich et al. believe that green tea plays a role in reducing chromosomal damage by apoptosis deduction, caspase activation, inhibition of protein kinases, cell cycle control and inhibits cell proliferation (33). Some are compared anti cancer properties of green tea to proteins that were binded to catechin. Proteins such as laminin receptor, laminin 67 (67 LR), vimentin, glucose reductase and fatty acid synthas connect to catechin and start a cascade of apoptosis processes in cancer cells. This inhibits formation and dispersion of cancer cells (34).

In another study, the cellular biological effects of epigallocatechin gallate is concentrated to direct inhibition of cycline dependent protein kinase, inhibits negative regulators of cell cycle and mitochondrial membrane depolarization (10).

Another catechin mechanisms at the molecular level are involved inhibition of growth factor receptors in cellular transmission pathways such as phosphatidyl inositol-3- kinase, protein kinase B, protein kinase of mitogen activated RAS/RAF, induce relaxation cycle cellular, induction of apoptosis and proteins that involved in cell cycle regulation (35).

According to reports, green tea increases plasma antioxidant levels, decreases plasma peroxide and oxidative DNA damage induced in human lymphocytes and improves antioxidative processes (36). Also, some studies show that green tea with its antioxidant property prevents cell membrane lipid peroxidation and biological systems and react against DNA damage and cancerous activity $(36,37)$. In another study has been named that degradation free radicals by catechin is the most important cause (16). EGCG could damage a very large number of free radicals such as active oxygen, superoxide anion, proxyl anion and active hydroxyl radicals (38). Some scientists are classified the effects of green tea catechins into two groups, inhibitory activity and stimulating activity. Inhibition of activities at the interaction with protein kinase $\mathrm{C}$, lipid peroxidation, angiogenesis, the formation of free radicals, ornitin decarboxylase, urokinase, lipo oxigenase, DNA polymerase, DNA topoisomerase, DNA gyrase, dopa carboxylase, alpha reductase steroid, catenin, P-glycoprotein, insulin-like growth factor receptor, telomerase, proteasomes, proteases and increase activities such as catalase, quinone reductase, phase enzyme and gap junctions are some of these activities $(39,40)$.

\section{Conclusions}

Tea is the second most common beverage in the world after water that has been used about 3-5 thousand years before Christ by Chinese people. Scientists are searching about its special properties that improve human health. Green tea can cause a very good balance in the body. Thus it prevents the risk of many diseases. The use of green tea have been used in the regulation of blood sugar, blood lipid, treating diseases such as variety of cancer and cardiovascular diseases from very ancient times in the Far East countries. Facilitating digestion, strengthen teeth and bones, immune enhancing, improvement of heart and lung function, inhibition of aging, disposal of toxic and hazardous types of viruses such as HIV and Hepatitis are among the benefits of green tea leaves. Daily consumption 3 cups of green tea are recommended for healthy individuals and consumption up to 10 cups of green tea for people whose have a variety of diseases, including cancer. According to researcher's studies, increase consumption of green tea have not the cytotoxic effects similar to chemotherapeutic agents and can be a suitable alternative for them (36). Researchers are emphasized to using green tea extract in the food production, especially children and young people's daily food. They believe that the use of green tea extract in foods such as bread, cakes, biscuits, pasta, sweets, snacks, ice cream and food products is easily achieved the most health of the population and reduce overall costs of treatment and maintenance of patients (32). Pro-oxidant and antioxidant properties of green tea can effective to neutralize the harmful effects of chemical-physical environmental pollutants such as electromagnetic radiation. Therefore, in order to promotion of health level and prevention of diseases spread, particularly cancer and reduce the costs of treatment, it is recommended to predict the daily consumption of green tea, with the exception of pregnant women.

\section{Acknowledgements}

Authors are thankful to Islamic Azad University of Mashhad for the assistance and support.

\section{Authors' Contributions}

All authors had equal role in design, work, statistical analysis and manuscript writing.

\section{Funding/Support}

Islamic Azad University of Mashhad has been supported the study.

\section{References}

1. Kundi M, Hardell L, Sage C, Sobel E. Electromagnetic fields and the precautionary principle. Environ Health Perspect. 2009;117(11):A484-5.

2. Khurana VG, Teo C, Kundi M, Hardell L, Carlberg M. Cell phones and brain tumors: a review including the long-term epidemiologic data. Surg Neurol. 2009;72(3):205-14.

3. Calvente I, Fernandez MF, Villalba J, Olea N, Nunez MI. Exposure to electromagnetic fields (non-ionizing radiation) and its rela- 
Zahedifar Z et al.

tionship with childhood leukemia: a systematic review. Sci Total Environ. 2010;408(16):3062-9.

4. Baharara J, Zahedifar Z. Effects of cell phones radiation on biological factors. J Cell Tissue. 2011;2(2):85-98.

5. Frazier ME, Reese JA, Morris JE, Jostes RF, Miller DL. Exposure of mammalian cells to $60-\mathrm{Hz}$ magnetic or electric fields: analysis of DNA repair of induced, single-strand breaks. Bioelectromagnetics. 1990;11(3):229-34.

6. Focke F, Schuermann D, Kuster N, Schar P. DNA fragmentation in human fibroblasts under extremely low frequency electromagnetic field exposure. Mutat Res. 2010;683(1-2):74-83.

7. Lambert JD, Elias RJ. The antioxidant and pro-oxidant activities of green tea polyphenols: a role in cancer prevention. Arch Biochem Biophys. 2010;501(1):65-72.

8. Sosa MV, Rodríguez-Rojo S, Mattea F, Cismondi M, Cocero MJ Green tea encapsulation by means of high pressure antisolvent coprecipitation. J Supercrit Fluids. 2011;56(3):304-11.

9. Sinija VR, Mishra HN. Fuzzy Analysis of Sensory Data for Quality Evaluation and Ranking of Instant Green Tea Powder and Granules. Food Bioprocess Tech. 2011;4(3):408-16.

10. Zahedifar Z, Baharara J. Effect of Green Tea Extract in Reducing Genotoxic Injuries of Cell Phone Microwaves on Bone Marrow. Zahedan J Res Med Sci. 2013;15(11):39-44

11. Liang J, Li F, Fang Y, Yang W, An X, Zhao L, et al. Response surface methodology in the optimization of tea polyphenols-loaded chitosan nanoclusters formulations. Eur Food Res Technol. 2010;231(6):917-24.

12. Miyagishima A, Fujiki S, Okimura A, Arahata S, Inagaki S, Iwao Y, et al. Novel decaffeination of green tea using a special picking method and shortening of the rolling process. Food Chem. 2011;125(3):878-83.

13. Nittby H, Brun A, Eberhardt J, Malmgren L, Persson BR, Salford LG. Increased blood-brain barrier permeability in mammalian brain 7 days after exposure to the radiation from a GSM-900 mobile phone. Pathophysiology. 2009;16(2-3):103-12.

14. Malhomme de la Roche H, Seagrove S, Mehta A, Divekar P, Campbell S, Curnow A. Using natural dietary sources of antioxidants to protect against ultraviolet and visible radiation-induced DNA damage: an investigation of human green tea ingestion.J Photochem Photobiol B. 2010;101(2):169-73.

15. Pastore RL, Fratellone P. Potential health benefits of green tea (Camellia sinensis): a narrative review. Explore (NY). 2006;2(6):531-9.

16. Sharangi AB. Medicinal and therapeutic potentialities of tea (Camellia sinensis L.) - A review. Food Res Int. 2009;42(5-6):529-35.

17. Yang CS, Wang H, Li GX, Yang Z, Guan F, Jin H. Cancer prevention by tea: Evidence from laboratory studies. Pharmacol Res. 2011;64(2):113-22.

18. Kubota M, Haga H, Takeuchi Y, Okuno K, Yoshioka H, Yoshioka H. Effect of tea catechins on the structure of lipid membrane and beta-ray induced lipid peroxidation. J Radioanal Nucl Ch. 2007;272(3):571-4.

19. Katiyar SK. Green tea prevents non-melanoma skin cancer by enhancing DNA repair. Arch Biochem Biophys. 2011;508(2):152-8.

20. Liu ML, Yu LC. Potential protection of green tea polyphenols against ultraviolet irradiation-induced injury on rat cortical neurons. Neurosci Lett. 2008;444(3):236-9.

21. Hu Y, Guo DH, Liu P, Cao JJ, Wang YP, Yin J, et al. Bioactive components from the tea polyphenols influence on endogenous antioxidant defense system and modulate inflammatory cytokines after total-body irradiation in mice. Phytomedicine. 2011; 18(11):970-5.

22. Kim MJ, Choi JH, Yang JA, Kim SY, Kim JH, Lee JH, et al. Effects of green tea catechin on enzyme activities and gene expression of antioxidative system in rat liver exposed to microwaves. Nutrition Res. 2002;22(6):733-44.
23. Kilicalp D, Dede S, Deger Y, Aslan L. Effects of green tea on mineral levels of liver and testis of Guinea pigs electromagnetic field emitted by mobil phones. Asian J Anim Vet Adv. 2009;4(2):86-92.

24. Kumaran VS, Arulmathi K, Kalaiselvi P. Senescence mediated redox imbalance in cardiac tissue: Antioxidant rejuvenating potential of green tea extract. Nutrition. 2009;25(7-8):847-54.

25. Baharara J, Parivar K, Ashraf AL. Effect of mobile phone microwaves (940 MHz) on hematopoietic system before birth. Sharekord Univ Med Sci. 2008;10(1):1-8.

26. Baharara J, Hadad F, Ashraf AL, Khanderoo E. The effect of extremely low frequency electromagnetic field $(50 \mathrm{~Hz})$ on induction of chromosomal damages on bone marrow erythrocytes of male Balb/C mouse. J Arak Univ Med Sci. 2008;11(2):19-26.

27. Baharara J, Hadad F, Shariatzade MA, Amirahmadi M. The genotoxic effects of mobile phone waves on induction of chromosomal damages in embryos of Balb/C mice. J Kermanshah Univ Med Sci. 2011;14(4).

28. Baharara S, Zahedifar Z, Haddad F, Mahdavi shari N. Effect of green tea on repressing chromosomal damage induced by cellphone $(940 \mathrm{MHz})$ waves in bone marrow polychromatic erythrocytes of male Balb/C mice. J Arak Univ Med Sci. 2012;15(1):10-7.

29. Zahedifar Z, Baharara J, Haddad F. Antioxidant effects of green tea extract in repressing of micronucleus formation in bone marrow polychromatic erythrocytes of male Balb/C mouse. Dev Biol J. 2010;2(6):59-64.

30. Baharara J, Mahdavi-Shahri N, Zafar-Balanejad S, Kamareh E. The Inhibitory Effect of Camellia sinensis Extract on Decreasing Inductive Teratogenicity of Low Frequency Electromagnetic Field in Liver and Spleen of Balb/C Rat Embryo. Zahedan J Res Med Sci. 2012;14(5):1-6.

31. Chan $\mathrm{KH}, \mathrm{Ho} \mathrm{SP}$, Yeung SC, So WH, Cho CH, Koo MW, et al. Chinese green tea ameliorates lung injury in cigarette smoke-exposed rats. Respir Med. 2009;103(11):1746-54.

32. Erba D, Riso P, Bordoni A, Foti P, Biagi PL, Testolin G. Effectiveness of moderate green tea consumption on antioxidative status and plasma lipid profile in humans. J Nutr Biochem. 2005;16(3):144-9.

33. Babich $\mathrm{H}$, Zuckerbraun $\mathrm{HL}$, Weinerman SM. In vitro cytotoxicity of (-)-catechin gallate, a minor polyphenol in green tea. Toxicol Lett. 2007;171(3):171-80.

34. Noda C, He J, Takano T, Tanaka C, Kondo T, Tohyama K, et al. Induction of apoptosis by epigallocatechin-3-gallate in human lymphoblastoid B cells. Biochem Biophys Res Commun. 2007;362(4):951-7.

35. Morita O, Kirkpatrick JB, Tamaki Y, Chengelis CP, Beck MJ, Bruner RH. Safety assessment of heat-sterilized green tea catechin preparation: a 6-month repeat-dose study in rats. Food Chem Toxicol. 2009;47(8):1760-70.

36. Ishii T, Mori T, Tanaka T, Mizuno D, Yamaji R, Kumazawa S, et al. Covalent modification of proteins by green tea polyphenol (-)-epigallocatechin-3-gallate through autoxidation. Free Radic Biol Med. 2008;45(10):1384-94.

37. Lu MJ, Chen C. Enzymatic modification by tannase increases the antioxidant activity of green tea. Food Res Int. 2008;41(2):130-7.

38. Regenerative effects of (-)-epigallocatechin-gallate against hepatic oxidative stress resulted by mobile phone exposure. In: Ozgur E, Güler G, Seyhan N editors. .11th Mediterranean Conference on Medical and Biomedical Engineering and Computing 2007. 2007 Springer: pp. 214-7.

39. Kuzuhara T, Suganuma M, Fujiki H. Green tea catechin as a chemical chaperone in cancer prevention. Cancer Lett. 2008; 261(1):12-20.

40. Yamauchi R, Sasaki K, Yoshida K. Identification of epigallocatechin-3-gallate in green tea polyphenols as a potent inducer of p53-dependent apoptosis in the human lung cancer cell line A549. Toxicol In Vitro. 2009;23(5):834-9. 